\title{
Safety and Potency Test for PV and ERA Based Cell Culture Anti-Rabies Vaccines Produced in Ethiopia
}

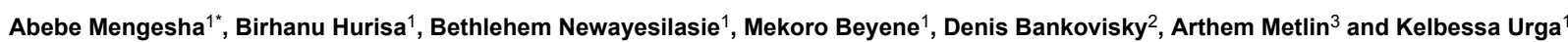 \\ ${ }^{1}$ Ethiopian Health and Nutrition Research Institute, Ethiopia \\ ${ }^{2}$ Pokrov Plant of Biologics, Russian Federation, Russia \\ ${ }^{3}$ Federal Center for Animal Health, Russian Federation, Russia
}

*Corresponding author: Abebe Mengesha, Ethiopian Health and Nutrition Research Institute, Ethiopia, Tel: 251 11 2133499 ; E-mail: agagurmu@yahoo.com or abebem@ehnri.gov.et

Received date: 14 April 2014; Accepted date: 19 June 2014; Published date: 24 June 2014

Copyright: ( $) 2014$ Mengesha A, et al. This is an open-access article distributed under the terms of the Creative Commons Attribution License, which permits unrestricted use, distribution, and reproduction in any medium, provided the original author and source are credited.

\begin{abstract}
This research was aimed to evaluate safety and potency of PV and ERA based cell culture anti-rabies vaccines. Two rabies vaccinal strains (PV and ERA) used to produce virus suspension propagated on Vero and BHK-21 cell lines. Potency and safety of the vaccine studied after inactivation with formalin. Safety test performed to access residual virulent left during inactivation or to detect any bacteriological contaminant present in the crude vaccine, and no residual virus or bacterial contaminant was detected. Potency test determines the degree of protection conferred by the vaccine in immunized mice challenged with challenge virus standard. This test was performed using National Institutes of Health (NIH) potency test. Mice were immunized on day 0 and 7 with five different concentrations of test vaccine and four different concentrations of control vaccine, 16 mice in each dilution. The control vaccine used was VeroRab vaccine which was produced by Sanofi Pasteur. Standard CVS strain obtained from CDC Atlanta was used for challenging. Mice were challenged on day 14th with challenge virus strain (CVS-11) of $25 \mathrm{MLD} 50 / 0.03 \mathrm{ml}$ intra-cerebrally. The mice were observed for 14 days and death recorded for each dilution separately. Potency result calculated using $\mathrm{NIH}$ test and $8.32 \mathrm{IU} / \mathrm{ml}$ for ERA and $3.56 \mathrm{IU} / \mathrm{ml}$ for PV results were obtained. Based on WHO recommendation, these vaccines have high potency and upon dilution can be used for animal immunization.
\end{abstract}

Keywords: Challenge virus; Inoculation; NIH test; Potency; Safety

\section{Introduction}

Rabies is a public health problem, approximately 50,000 humans worldwide die from the disease annually $[1,2]$. Most of the persons at risk live in 90 countries with a population of 2.4 billion, where the rabies reservoir is the dog. In these areas, more than 95 percent of human rabies cases are transmitted by dogs [3]. In Ethiopia, 94.01 percent of rabies cases are caused due to the bite of rabid dogs and the rest cases incriminate domestic and wild animals [4]. Consequently, vaccination of dogs considerably reduces the risk to human, as has been shown in Europe and the USA [5].

Since the first rabies vaccination in 1885 by Louis Pasteur, significant progress has been made in improving the pre and postexposure treatment of human rabies [3]. Several types of anti-rabies vaccines are used for pre and post exposure treatment, which include live attenuated which is live virus after several passage, inactivated (killed), DNA-based and vector vaccines. For the production of antirabies vaccines, a number of attenuated vaccine strains are employed. These are Pasteur Virus (PV), Evelyn RokitnikiAbelseth (ERA), StreetAlabama-Dufferin (SAD), 3aG, Pitman Moore (PM), and Flury strains [6]. PV strain is one of the first vaccine strains, which was isolated from a rabid cow in 1882 and attenuated by multiple passages in rabbit brain. The SAD strain was isolated from a rabid dog in Alabama (USA) in 1935 and adapted for cultivation on the mouse brain and on the baby hamster kidney cell culture (BHK) [7].
Although the need for evaluating the immunizing potencies of rabies vaccines has been recognized since the early Pasteur days and practical standardized tests have been available and in use for over 20 years, many laboratories that produce the vaccines did not practice routine test on the potency of their products.

Following a standard vaccine production procedure alone does not necessarily assure production of vaccines with consistently satisfactory potency levels. There are three important considerations in assessing any potency test of rabies vaccines. First, the test procedure should actually evaluate the property of the vaccine that determines its effectiveness in the prophylaxis of rabies in human or animals. Using a naturally susceptible host, the ideal test would simulate conditions of natural exposure and usual prophylactic treatment [2]. This would mean the use of street virus introduced through a bite-wound, followed by daily doses of vaccine in the case of those vaccines intended for human use. This has, of course, been found to be impractical, as have most types of test where administration of vaccine is started after experimental exposure of the test animal. Most tests, therefore, involve multiple doses of vaccine (as administered in human) followed by subsequent challenge with fixed virus given intracerebrally, as being a more easily standardized type of challenge. While far from reproducing the situation with natural exposure and the standard schedule of vaccine administration, this type of test has been shown to reflect fairly closely the ability of a vaccine to protect under natural conditions [8]. Secondly, not all laboratories can obtain large numbers of experimental animals easily, nor they could repeat tests when animal costs are high. The time factor is important, since newly prepared vaccine must be held until potency tests are complete and the 
time required for this has to be deducted from its period of effectiveness [2]. The third requirement is for standardization of the test procedure so that there will be comparability of results from one vaccine to another in a single laboratory and between different laboratories [6]. The aim of this study to evaluate safety and potency of cell culture anti-rabies vaccine produced in Ethiopia by in vivo method on suckling mice.

\section{Materials and Methods}

\section{Experimental animals}

Ten to sixteen gram weight, 2 weeks of age Swiss albino mice with identical sex were used for both safety and potency test.

\section{Inactivation}

The viral suspension was thawed and centrifuged at $5000 \mathrm{rpm}$ for 15 minute to remove cell debris. Formalin inactivation was performed by using concentration of 1:5000 vol/vol, formalin and incubating at $37^{\circ} \mathrm{C}$ for $48 \mathrm{~h}$, shaking twice a day.

\section{Safety test}

Presences of residual virus were investigated on three groups of mice, each group containing eight mice. The mice were inoculated with $30 \mu \mathrm{l}$ of test vaccine intra-cerebrally for each dilution and observed for 14 days for any sign of infection by rabies. Bacteriological test was performed by incubating test vaccine in thioglycolate media for 48 hours.

\section{Potency test}

Potency test was performed using National Institutes of Health $(\mathrm{NIH})$ test. Mice were immunized at day 0 and 7 with $0.5 \mathrm{ml}$ of both test and reference vaccine intra-peritoneal. Five different concentrations of test vaccine $(1: 5,1: 25,1: 125,1: 625$ and 1:3125) and four different concentrations of reference vaccine $(1: 10,1: 50,1: 250$ and 1:1250), 16 mice in each dilution were used. The control vaccine used was VeroRab vaccine which was produced by Sanofi Pasteur. This vaccine was converted to $1 \mathrm{IU}$ before preparing working dilution for immunization. Forty mice were kept separately from immunized group to be used as control.

\section{Challenge test}

Standard challenge virus strain (CVS-11), which was obtained from CDC Atlanta was used for challenging. All mice; test, reference and control group were challenged on 14th day of immunization with challenge virus strain (CVS-11) of $25 \mathrm{MLD} 50 / 0.03 \mathrm{ml}$. The mice were observed for 14 days after challenge. Any mouse that died within five days after challenge was recorded as non specific death. Mice that died after fifth day of challenging without showing sign of rabies was tested by fluorescent antibody test (FAT) for presence of any detectable rabies virus on the brain sample. All specific and non specific deaths were recorded separately.

\section{Data analysis}

Data analysis was performed using NIH formula to calculate potency of crude vaccine. The recorded number of mice that died and survived was used to estimate relative potency (RP). The potency was calculated using the number of mice that survived and mice died with specific death and non specific death, which was recorded separately after 14 days of challenging.

A volumetric method of calculation of potency, compares the $50 \%$ end-point dilution (vaccine dilution protecting $50 \%$ of mice) of the vaccine under test with that of the standard (commercial vaccine diluted to a final potency of $1 \mathrm{IU} / \mathrm{ml}$ ). The relative potency (RP) of the vaccine under test was determined by the formula:

$$
\mathrm{RP}=\frac{\text { reciprocal of } \mathrm{ED} 50 \text { of } \mathrm{TV}}{\text { reciprocal of } \mathrm{ED} 50 \text { of } \mathrm{RV}} \times \frac{\text { dose of } \mathrm{TV}}{\text { dose of } \mathrm{RV}}
$$

\section{Result and Discussion}

For the safety test, all mice survived the intracerebral inoculation with three different dilutions of the test vaccine. These mice were observed for 14 days after inoculation and no death recorded. This implies that the vaccine is completely inactivated and there was no residual virus present in the crude vaccine. Bacteriological safety test shows no growth of contaminant after inoculation of the crude vaccine on thioglycolate bacteriological media which guarantees the safety of the crude vaccine at this level of purification (Table 1).

\begin{tabular}{|c|c|c|c|c|c|c|}
\hline Type & $\begin{array}{l}\text { Group } \\
\text { name }\end{array}$ & $\begin{array}{l}\text { No. } \\
\text { mice }\end{array}$ & Dilution & Death & Survival & Non-SD \\
\hline \multirow{5}{*}{$\begin{array}{l}\text { Test vaccine } \\
\text { (formalin } \\
\text { inactivated) }\end{array}$} & Gr-1 & 16 & $1: 5$ & 2 & 14 & - \\
\hline & Gr-2 & 16 & $1: 25$ & 3 & 13 & - \\
\hline & Gr-3 & 16 & $1: 125$ & 4 & 12 & - \\
\hline & Gr-4 & 16 & $1: 625$ & 4 & 11 & - \\
\hline & Gr-5 & 16 & $1: 3125$ & 9 & 7 & - \\
\hline \multirow{4}{*}{$\begin{array}{l}\text { Reference } \\
\text { vaccine }\end{array}$} & Gr-6 & 16 & $1: 10$ & 6 & 10 & - \\
\hline & Gr-7 & 16 & $1: 50$ & 6 & 10 & - \\
\hline & Gr-8 & 16 & $1: 250$ & 12 & 4 & - \\
\hline & Gr-9 & 16 & $1: 1250$ & 11 & 5 & - \\
\hline \multirow{3}{*}{ Control } & Gr-10 & 8 & $10-1$ & 6 & 2 & - \\
\hline & Gr-11 & 8 & $10-2$ & 3 & 4 & 1 \\
\hline & Gr-12 & 8 & $10-3$ & 0 & 8 & - \\
\hline
\end{tabular}

Table 1: The result of potency for formalin inactivated vaccine. SDspecific death, Gr-group

This table briefly explains the number of mice died from each group with differentiation between specific and non specific death. Control group included to evaluate the effect of virus on non vaccinated group.

The findings revealed that mice died from all dilutions but the number of mice died differs with in dilutions for both test and reference vaccines. As dilution step increased, the number of mice died increased within each dilution except reference vaccine with two dilutions resulted in similar death and survival rate. Slight difference of potency result was obtained for both ERA and PV strain vaccines. Potency result shows relative potency of $8.32 \mathrm{IU} / \mathrm{ml}$ for ERA rabies vaccinal strain and $3.56 \mathrm{IU} / \mathrm{ml}$ for PV rabies virus vaccinal strain. Based on WHO's recommendation, both vaccines show potency result above the requirement which is greater than $2.5 \mathrm{IU} / \mathrm{ml}$ for single dose 
Citation: Mengesha A, Hurisa B, Newayesilasie B, Beyene M, Bankovisky D, et al. (2014) Safety and Potency Test for PV and ERA Based Cell

of immunization. ERA rabies virus strain showed high potency when compared to PV rabies virus strain. This can be expressed based on the virus titer before inactivation which can be 106-108 TCID/ml and the virus genetic activity difference. Therefore, PV vaccinal strain produced vaccine can be used as it is, and ERA vaccinal strain based vaccine should be diluted up to the lower minimum potency requirement to use as single dose of vaccination.

\section{Conclusion}

The study showed that both ERA and PV vaccinal strain based vaccines are free from any residual virus left after inactivation and no bacterial contamination during the process of production. The ERA and PV strain vaccines were effective at $8.32 \mathrm{IU} / \mathrm{ml}$ and $3.56 \mathrm{IU} / \mathrm{ml}$, respectively. These crude vaccines fulfill the potency and safety requirement of rabies vaccine based on WHO recommendation. The vaccines can therefore be used for animal immunization, but further purification is required to be used for human.

\section{Acknowledgement}

We would like to thank Dr. Artem Metlin and Dr. Denis Bankovskiy for their technical assistance; Centers for Disease Control and Prevention, (CDC) Atlanta, for their kind donation of rabies virus strain and Twinning Center for financial support to our mentors.

\section{References}

1. WHO (1987) World Health Organization Expert Committee on Biological Standards. Thirty-Fifth Report 1985. World Health Organization Technical Report Series No. 725, Geneva.

2. WHO (2013) World Health Organization Expert Consultation on Rabies. Eighth Report 1992. World Health Organization Technical Report Series No. 824.

3. Yimer E (2001) Rabies in Ethiopia, Sixth SEARG meeting.

4. Tefera G, Yimer E, Geyid A (2002) Endemic existence of rabies in Ethiopia. Ethiop Med J 40: 163-170.

5. Branche R (1996) Vaccine for humans prepared in human diploid cells. 280-284.

6. WHO (1994) Requirements for rabies vaccine (inactivated) for human use produced in continuous cell lines (amendment 1992). WHO Expert Committee on Biological Standardization. Forty-third report. Geneva.

7. Metlin A, Paulin L, Suomalainen S, Neuvonen E, Rybakov S, et al. (2008) Characterization of Russian rabies virus vaccine strain RV-97. Virus Res 132: 242-247.

8. Cliquet F, Aubert M, Sagné L (1998) Development of a fluorescent antibody virus neutralisation test (FAVN test) for the quantitation of rabies-neutralising antibody. J Immunol Methods 212: 79-87. 